\title{
The concept of colloidal stabilization of wines
}

\author{
Olga Chursina*, Viktor Zagorouiko
}

Federal State Budget Scientific Institution All-Russian National Research Institute of Viticulture and Winemaking Magarach of the RAS, 31 Kirova Str., 298600 Yalta, Republic of Crimea, Russia

\begin{abstract}
Colloidal haze in wines is the most difficult technological and economic problem of wine industry. A number of modern technological means are used to prevent its formation, but the problem still exists. The main role in wine destabilization is played by colloidal substances proteins, polysaccharides, phenolic compounds, which, when interacting, can form a complex of biopolymers. The aim of the study is to substantiate a new strategy for preventing colloidal haze in wines by regulating the composition of a complex of biopolymers. We used conventional and special methods of analysis to isolate and study wine proteins and related components. As a result of the research, 5 types of a complex of biopolymers were identified and studied. Basic factors causing their instability are critical mass concentration of a complex of biopolymers and its constituents, high-molecular weight of proteins and polyphenol oxidation. We propose a concept for preventing colloidal haze in wines, including a decrease in the content of a complex of biopolymers by targeting its dominant component at the first stage, an increase in the proportion of polysaccharides in the composition of a complex of biopolymers at the second stage, and protection of phenolic component from oxidation at the final stage.
\end{abstract}

\section{Introduction}

Stabilization of wine colloidal substances is a big problem for winemakers, since their aggregation leads to the formation of haze and market quality loss of the finished product, as well as reclamation from distributing facilities - to significant economic losses and damage to the image of manufacturer. Despite modern achievements in science and practice, strategic issues of ensuring the colloidal stability of wines are not completed yet and remain relevant up to date [1-6].

According to modern concepts, a modeling role in the formation of wine haze is played by various biopolymers - proteins, polysaccharides, phenolic substances, but many other wine components are also involved [1-6]. The conceptual model of protein-tannin interaction is considered as the main matrix for colloidal haze formation [3, 7]. Proteins are present in wine in the amount from 15 to $300 \mathrm{mg} / \mathrm{dm}^{3}[2,4,8,9]$ as grape proteins of various molecular weights (from 6 to $200 \mathrm{kD}$ ) [10]. Most often precedents are created by proteins associated with grape pathogenesis (chitinases and thaumatin-like proteins) with molecular weight from 10 to $40 \mathrm{kD}$ and isoelectric point below $6[1,8,11,12]$. These

\footnotetext{
*Corresponding author: olal45@mail.ru
} 
proteins are resistant to proteolysis, high ethanol content and low $\mathrm{pH}$ of must and wines, and because of the similar charge with bentonite they cannot be removed during technological processing, being potential sources of haze in wine after bottling [13].

The process of protein aggregation is influenced by various factors: characteristics of wine proteins (structure, molecular size and hydrophobic properties), wine composition and storage conditions (temperature, $\mathrm{pH}$, ionic strength, content of ethanol, organic acids and metals), considering that non-protein wine compounds are of decisive importance (polyphenols and/or polysaccharides) [4, 7]. The value of the resulting protein haze depends not only on the content of protein and polyphenol, but also on their ratio [8]. Polysaccharides are basic high-molecular wine components that can potentially reduce protein aggregation in wines by forming a protective layer around intrinsically disordered proteins; however, the role of polysaccharides in the development of haze is variable [1416]. Some polysaccharides, interacting directly with proteins or polyphenols, cause precipitation, others - delay the reaction between proteins and other macromolecules, depending on their concentration $[4,16,17]$. The detailed aggregation mechanism of these proteins, especially in combination with other wine components, remains unclear.

Various physicochemical methods and technological means (filtration, treatment with cold, heat, bentonite, gelatin, tannin, etc.) are used to stabilize wine [7], however, they do not always allow achieving a significant effect, which is associated with the peculiarities of a complex of biopolymers involved in haze formation, and necessity to control their composition to ensure wine stability.

The aim of the research was to substantiate a new strategy for preventing colloidal haze in wines by regulating the composition of a complex of biopolymers.

\section{Materials and Methods}

The research materials we used were wines from different grape varieties, prepared using various technologies (crushing with/without ridge separation, with/without maceration, with/without thermal treatment), wine processing techniques (heat, cold, fining) and agents (silicon dioxide, bentonite, tannin, gelatin, specific enzyme preparations, etc.).

Standard and special methods (chromatography, electrophoresis, spectrophotometry, potentiometry, etc.) were used for physicochemical analysis of wines, isolation and study of a complex of biopolymers. The range of wine tendency to colloidal haze was assessed using various tests (tannin, heat, cold).

Methods of mathematical statistics (correlation, regression, discriminant analyzes) with the help of modern computer technologies were used to process the data obtained.

\section{Results and Discussion}

As the analysis of non-market-quality defective wines showed, the greatest problem was presented by colloidal substances, forming haze and sediments in more than $40 \%$ of cases. Proteins, polyphenols, pectin, ions of some metals (calcium, iron) and anions (sulfates, phosphates) were found in wine sediments.

The proteins were isolated from wine using carbonaceous resin with further wine testing for its tendency to colloidal haze. It was found that during sorption, along with proteins, the polyphenols and polysaccharides were also released, forming a biopolymer structure in combination with proteins. Removal of this biopolymer complex from wine was leading to a decrease in the value of colloidal haze, determined by tests, down to zero values. This indicated the important role of the studied protein-polyphenol-polysaccharide complex in the formation of colloidal haze. Moreover, depending on wine technology and production 
methods used, the constituents of this structure differed in a number of characteristics: the ratio of polyphenols to proteins, molecular weight of proteins, the proportion of polysaccharides, and the indicator of polyphenol oxidation ability (Table).

Table. Complex of biopolymers of different types of wine.

\begin{tabular}{|c|c|c|c|c|c|}
\hline \multirow{2}{*}{$\begin{array}{l}\text { Complex of } \\
\text { biopolymers }\end{array}$} & \multicolumn{3}{|c|}{ Mass concentration, $\mathrm{mg} / \mathrm{dm}^{3}$} & \multirow{2}{*}{$\begin{array}{c}\text { Indicator of } \\
\text { oxidation } \\
\text { ability }\end{array}$} & \multirow{2}{*}{ Wines } \\
\hline & proteins & polyphenols & polysaccharides & & \\
\hline I & $\frac{5-35}{20}$ & $\frac{4-17}{9}$ & $\frac{7-48}{26}$ & $\frac{20-25,7}{22,4}$ & $\begin{array}{l}\text { light white and } \\
\text { sparkling }\end{array}$ \\
\hline II & $\frac{0,7-17}{9}$ & $\frac{9-61}{19}$ & $\frac{6-101}{25}$ & $\frac{18-23,3}{20,3}$ & white big \\
\hline III & $\frac{6-63}{22}$ & $\frac{9-47}{21}$ & $\frac{53-115}{79}$ & $\frac{1,9-6,3}{4,4}$ & white fortified \\
\hline IV & $\frac{11-81}{49}$ & $\frac{11-90}{52}$ & $\frac{26-343}{135}$ & $\frac{0,8-5,4}{1,96}$ & red fortified \\
\hline $\mathrm{V}$ & $\frac{6-57}{14}$ & $\frac{7-48}{29}$ & $\frac{0-230}{25}$ & $\frac{0,1-3,1}{1,1}$ & red \\
\hline
\end{tabular}

Biopolymer structures of white and sparkling wines were distinguished by predominance of protein-polysaccharide fraction with a low proportion and oxidation degree of phenolic component. The molecular weight of protein fractions varied over a wide range (10-67 $\mathrm{kD}$ and higher), while the proportion of high-molecular proteins was up to $20 \%$.

With an increase in wine extractability (fortified and red wines), the polyphenolpolysaccharide fraction begins to dominate in the a complex of biopolymers in the composition with oxidized forms of phenolic compounds along with a medium- and lowmolecular protein content (less than $43 \mathrm{kD}$ ).

Wines with a complex of biopolymers I and II are prone to the formation of irreversible colloidal haze, and a complex of biopolymers III-V are responsible for the formation of reversible colloidal haze, occurring with wine cooling and disappearing with its further warming. A high proportion of polysaccharides in their composition and a low-molecular weight of proteins contribute to an increase in aggregate stability of a complex of biopolymers in comparison with previous ones. However, as time is extended, reversible colloidal haze turn to irreversible one.

Sediments in wine are formed during transformation of a complex of biopolymers, which is accompanied by an increase in mass concentration of protein and polyphenol components and/or by oxidation of polyphenols, and leads to a loss of its solubility. Oxidation of phenolic compounds contributes to an increase in the protein affinity and enhances the tannin-protein interaction, and the participation of high-molecular weight proteins accelerates aggregation of this complex.

Wine technology and the techniques used impact the composition of a complex of biopolymers, which is significant for white wines when crushing grapes and separating must by pressing; for red and fortified wines - with prolonged contact of must with pulp during infusion and/or fermentation. Since the certain type of wine preparation requires a number of basic operations, it limits the possibility of regulating the composition of a complex of biopolymers at the stage of production and necessitates further processing of wines for stabilization.

Our studies made it possible to reveal the relationship between a complex of biopolymers and technological schemes of wine processing. The high content of proteins with low- and medium-molecular weight along with a low proportion of phenolic 
compounds and polysaccharides in a complex of biopolymers I determined the effectiveness of using sodium bentonite, which has a high surface charge (individually or in combination with gelatin), to reduce mass concentration of the complex and ensure the stability of wine (Fig. 1).

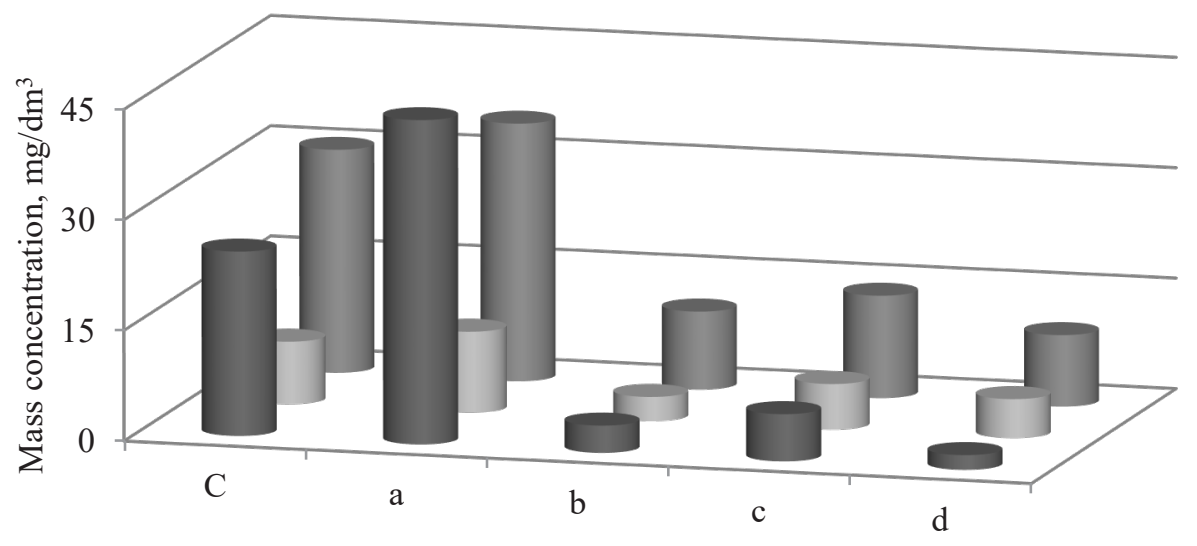

" proteins $\square$ polyphenols $\quad$ polysaccharides

Fig. 1. Changes in the a complex of biopolymers I and II (white wines) during treatments with: a) gelatin; b) bentonite; c) silicon dioxide and gelatin; d) gelatin and bentonite; $\mathrm{C}$ - control.

With an increase in the proportion of polyphenols in the a complex of biopolymers II, prevailing over the protein content, it is advisable to use complex treatment of wine with gelatin and bentonite (or their analogs). And the presence of high-molecular weight proteins made it necessary to include in the processing scheme the tannin (gallotannin), which has a high affinity for them. The most significant effect on aggregation of a complex of biopolymers was influenced by heat treatment of wine $\left(65+5^{\circ} \mathrm{C}\right)$, as highly effective for difficult-to-process white wines.

An increase in the mass concentration of proteins in the a complex of biopolymers III with a decrease in their molecular weight led to an increase in the dose of gluing agents (gelatin and bentonite). Considering polyphenol predominance in the a complex of biopolymers IV and V with a high degree of oxidation, the most effective are preparations of selective action - polyvinylpolypyrrolidone or gelatin with a short molecular chain (enogelatin), as well as combined treatment with fining agents and cold. The positive effect of cold treatment consisted not only in the aggregation of the most unstable tannin-protein complexes as a result of losing their solubility, but also in an increase in the proportion of polysaccharides in their composition (Fig. 2). Moreover, the higher the proportion of polysaccharides in the structure of biopolymers, the more stable this structure is, and the timeline of wine stability is longer $(\mathrm{r}=0.945, \mathrm{R} 2=0.893)$. It is established that stabilizing effect of polysaccharides is manifested with their significant predominance in the composition of a complex of biopolymers in relation to the protein (not less than 3 times). This important research result explains the dual role of polysaccharides in wine, which can both contribute to haze and have a protective effect against it.

The introduced exogenous polysaccharides (especially acidic) also increase the stability of a complex of biopolymers in wine due to the inclusion in their composition. With a permissible dose of gum-arabic (100-300 mg/dm ${ }^{3}$ ), the content of polysaccharides in the a complex of biopolymers increases by 3-4 times, which significantly prolongates the period of wine stability. 
It should be noted that high content of polysaccharides in the a complex of biopolymers in untreated wines complicates their stabilization and necessitates using of pectolytic enzyme preparations.

The mechanism of colloidal stabilization of wines, which consists in increasing the solubility and stability of the structure of biopolymers by reducing the content of proteins, as well as phenolic compounds $(<15 \%)$ and their degree of oxidation with an increase in the content of polysaccharides ( $>60 \%)$, was substantiated [18].

Enrichment of wine with atmospheric oxygen in the process of technological treatments (during pumping, agitation and filtration) leads to intensification of oxidative processes and increasing the proportion of oxidized forms of phenolic substances in the a complex of biopolymers, resulting in the haze of bottled wine. Therefore, an important element of wine stabilization technology is the prevention of further oxidation of phenolic component in the a complex of biopolymers, which is achieved by using increased measures of protection the processed wine from oxidation. The only exclusion of operation of wine resting after technological treatments, which is carried out according to technological instruction during 10 days, made it possible to improve the stability of bottled wines by $37 \%$, especially red liqueur wines (by 1.5 times and more) (Fig. 3) [19].

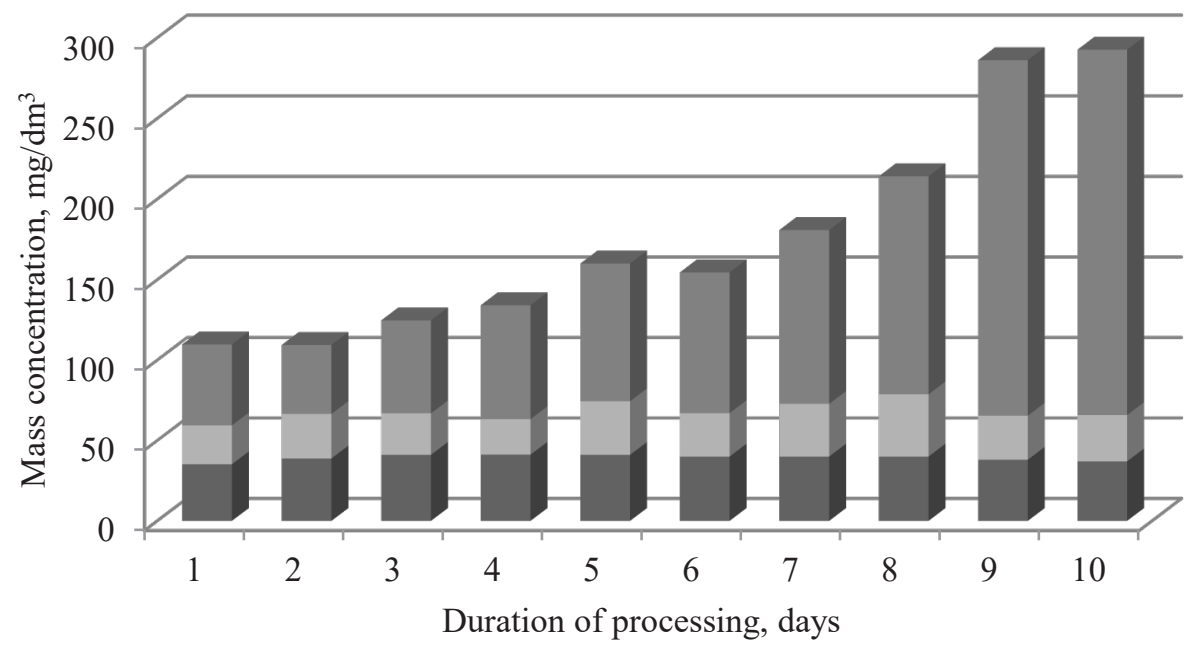

- proteins $\square$ polyphenols $\square$ polysaccharides

Fig. 2. The effect of cold processing on the composition of wine a complex of biopolymers.

We propose a strategy to prevent colloidal haze of wines based on regulating the composition of a complex of biopolymers, which includes:

at the first stage - a decrease in the mass concentration of a complex of biopolymers by targeting the dominant component, in particular, proteins of low- and medium-molecular weight - by preparations for fining with a high surface charge (bentonite, gelatin); highmolecular proteins - by additional introduction of selective polymeric flocculants (gallotannins); phenolic components of the complex - by preparations with increased amount of amino acid residues (enogelatin), polyvinylpolypyrrolidone; and polysaccharides - by pectolysis (treatment with enzyme preparations of special purpose) or heat treatment;

at the second stage - an increase in the proportion of polysaccharides in the a complex of biopolymers due to enrichment with exogenous polysaccharides (gum-arabic, etc.) or endogenous polysaccharides (cold treatment); 
and at the final stage - strengthening measures to protect the phenolic component of a complex of biopolymers from oxidation (exclusion of the resting operation, introduction of sulfur dioxide, storage under inert gases).

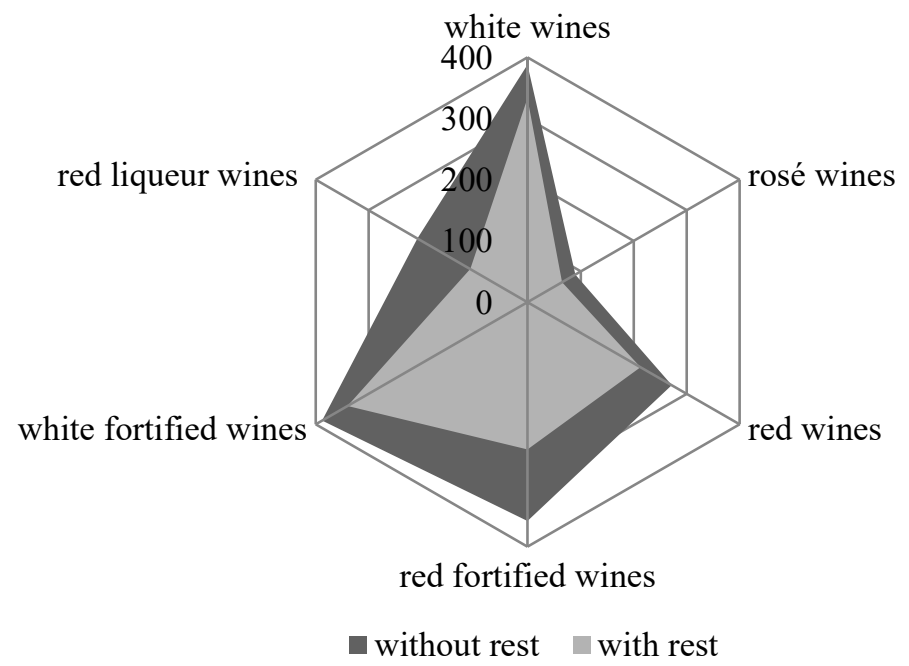

Fig. 3. The effect of wine resting operation on the terms of stability (days)

\section{Conclusion}

The studies provided show that tannin-protein complexes, which also include polysaccharides, are the basis for colloidal haze formation. The revealed a complex of biopolymers were divided into five groups, their properties were thoroughly studied. For white and sparkling wines, such a complex of biopolymers are characteristic, in which the protein-polysaccharide fraction with a high proportion of high-molecular proteins (up to $20 \%$ ) prevails, and in the composition with phenolic component - in non-oxidized form. In the a complex of biopolymers of red and fortified wines the dominant role belongs to polyphenol-polysaccharide fraction in the composition with low-molecular proteins (less than $43 \mathrm{kD}$ ) and oxidized forms of phenolic compounds.

The mechanism of colloidal stabilization of wine, which consists in increasing the stability of a complex of biopolymers by reducing the content of protein and oxidized forms of phenolic compounds $(<15 \%)$ with an increase in the proportion of polysaccharides $(>60 \%)$ in its composition, is substantiated.

Optimal processing schemes for different types of wines, depending on the a complex of biopolymers, were developed. A concept of wine colloidal stabilization based on regulating the composition of a complex of biopolymers, including a decrease in the content of a complex of biopolymers by targeting the dominant component at the first stage, an increase in the proportion of polysaccharides in the structure of biopolymers at the second stage, and protection of phenolic component from oxidation at the final stage, was proposed.

The study results elaborate theoretical foundations of wine stabilization technology and demonstrate the importance of developing new strategies to prevent wine haze in modern conditions of severe competition to ensure high quality, increase production efficiency and reduce environmental impact. 


\section{References}

1. M. Meier, N. Jaeckels, S. Tenzer, M. Stoll, H. Decker, P. Fronk, F. Will, European Food Res. and Technol., 242 (11), 1883-1891 (2016)

2. J. M. McRae, A. Schulkin, R. G. Dambergs, P. A. Smith, Aust. J. Grape Wine Res., IF2.688, 1-6 (2018)

3. B. Tian, R. Harrison, Chemistry and Biochemistry of Winemaking, Wine Stabilization and Aging, 1-18 (Publisher: InthecOpen, 2020)

4. M. Marangon, S. C. Van Sluyter, K. A. Neilson, C. Chan, P. A. Haynes, E. J. Waters, R. J. Falconer, Journal of Agricultural and Food Chemistry, 59 (2), 733-740 (2011)

5. M. Dufrechou, C. Poncet-Legrand, F.-X. Sauvage, A. Vernhet, Journal of Agricultural and Food Chemistry, 60 (5), 1308-1319 (2012)

6. S. C. Van Sluyter, J. M. McRae, R. J. Falconer, P. A. Smith, A. Bacic, E. J. Waters, M. Marangon, Journal of Agricultural and Food Chemistry, 63 (16), 4020-4030 (2015)

7. F. Cosme, L. Filipe-Ribeiro, F. M. Nunes, Chemistry and Biochemistry of Winemaking, Wine Stabilization and Aging, 1-32 (Publisher: InthecOpen, 2021)

8. F. Cosme, C. Fernandes, T. Ribeiro, L. Filipe-Ribeiro, F. M. Nunes, Beverages, 6 (1), 1-19 (2020)

9. E. Romanini, J. M. McRae, E. Bilogrevic, D. Colangelo, M. Gabrielli, M. Lambri, Food Chemistry, 341, 128250 (2021)

10. M. Santoro, Am. J. Enol. Vitic., 46, 250-254 (1995)

11. R.B. Ferreira, M.A. Piçarra-Pereira, S. Monteiro, V.B. Loureiro, A.R. Teixeira, Trends Food Sci. Technol., 12, 230-239 (2002)

12. S.P. Robinson, C. Davies, Aust. J. Grape Wine Res., 6, 175-188 (2000)

13. R.B. Ferreira, S. Monteiro, M.A. Piçarra-Pereira, A.R. Teixeira, Trends Biotechnol., 22, 168-173 (2004)

14. D. Gazzola, S. C. Van Sluyter, A. Curioni, E. J. Waters, M. Marangon, Journal of Agricultural and Food Chemistry, 60 (42), 10666-10673 (2012)

15. T. Ribeiro, C. Fernandes, F. M. Nunes, L. Filipe-Ribeiro, F. Cosme, Food Chemistry, 159, 47-54 (2014)

16. N. Jaeckels, M. Meier, H. Dietrich, F. Will, H. Decker, P. Fronk, Food Chemistry, 200, 38-45 (2016)

17. M. Dufrechou, T. Doco, C. Poncet-Legrand, F.-X. Sauvage, A. Vernhet, Journal of Agricultural and Food Chemistry, 63 (45), 10042-10053 (2015)

18. O. Chursina, V. Zagoruiko, Magarach. Viticulture and Winemaking, 20 (3), 98-100 (2018)

19. O. Chursina, V. Zagoruiko, Viticulture and Winemaking, 20 (3), 32-35 (2018) 